\title{
Associations of dietary carbohydrates, glycaemic index and glycaemic load with risk of bladder cancer: a case-control study
}

\author{
Livia S. A. Augustin ${ }^{1,2 *}$, Martina Taborelli ${ }^{3}$, Maurizio Montella ${ }^{1}$, Massimo Libra ${ }^{4}$, Carlo La Vecchia ${ }^{5}$, \\ Alessandra Tavani ${ }^{6}$, Anna Crispo ${ }^{1}$, Maria Grimaldi ${ }^{1}$, Gaetano Facchini ${ }^{7}$, David J. A. Jenkins ${ }^{2,8,9,10}$, \\ Gerardo Botti ${ }^{1}$, Diego Serraino ${ }^{3}$ and Jerry Polesel ${ }^{3}$ \\ ${ }^{1}$ National Cancer Institute 'Istituto Nazionale Tumori Fondazione Giovanni Pascale', Istituto di Ricovero e Cura a Carattere \\ Scientifico (IRCCS), Via Mariano Semmola 1, 80131 Naples, Italy \\ ${ }^{2}$ Clinical Nutrition and Risk Factor Modification Center, St. Michael's Hospital, 61 Queen Street East, Toronto, \\ ON M5C 2T2, Canada \\ ${ }^{3}$ Cancer Epidemiology Unit, Istituto di Ricovero e Cura a Carattere Scientifico (IRCCS) Centro di Riferimento Oncologico, Via \\ F. Gallini 2, Aviano, 33081 PN, Italy \\ ${ }^{4}$ Section of Clinical \& General Pathology \& Oncology, Department of Biomedical E Biotechnological Sciences, University \\ of Catania, Via Androne 83, 95124 Catania, Italy \\ ${ }^{5}$ Department of Clinical Sciences and Community Health, Università degli Studi di Milano, Via Vanzetti, 5, 20133 Milan, Italy \\ ${ }^{6}$ Istituto di Ricovero e Cura a Carattere Scientifico (IRCCS) Istituto di Ricerche Farmacologiche 'Mario Negri', Via La Masa 19, \\ 20156 Milan, Italy \\ ${ }^{7}$ Uroginecology Unit, National Cancer Institute, G. Pascale Foundation, 80131 Naples, Italy \\ ${ }^{8}$ Department of Nutritional Sciences, Faculty of Medicine, University of Toronto, 150 College Street, Toronto, ON M5S 3E2, Canada \\ ${ }^{9}$ Division of Endocrinology and Metabolism, St. Michael's Hospital, Toronto, ON M5C 2T2, Canada \\ ${ }^{10} \mathrm{Li}$ Ka Shing Knowledge Institute, St. Michael's Hospital, 209 Victoria Street, Toronto, ON M5B 1T8, Canada
}

(Submitted 19 February 2017 - Final revision received 29 August 2017 - Accepted 4 September 2017-First published online 9 October 2017)

\section{Abstract}

Carbohydrate foods with high glycaemic index (GI) and load (GL) may negatively influence cancer risk. We studied the association of dietary carbohydrates, GI, GL, intake of bread and pasta with risk of bladder cancer using data from an Italian case-control study. The study included 578 men and women with histologically confirmed bladder cancer and 608 controls admitted to the same hospitals as cases for acute, non-neoplastic conditions. OR were estimated by logistic regression models after allowance for relevant confounding factors. OR of bladder cancer for the highest $v$. the lowest quantile of intake were 1.52 (95\% CI 0.85, 2.69) for available carbohydrates, 1.18 (95\% CI 0.83, 1.67) for GI, 1.96 (95\% CI 1.16, 3.31, $\left.P_{\text {trend }}<0.01\right)$ for GL, $1.58\left(95 \%\right.$ CI 1.09, 2.29, $\left.P_{\text {trend }}=0.03\right)$ for pasta and $1.92\left(95 \%\right.$ CI 1.28, 2.86, $\left.P_{\text {trend }}<0.01\right)$ for bread. OR for regular consumption of legumes and whole-grain products were $0.78(95 \% \mathrm{CI} 0.60,1.00)$ and $0.82(95 \% \mathrm{CI} 0.63,1.08)$, respectively. No heterogeneity in risks emerged across strata of sex. This case-control study showed that bladder cancer risk was directly associated with high dietary GL and with consumption of high quantity of refined carbohydrate foods, particularly bread. These associations were apparently stronger in subjects with low vegetable consumption.

Key words: Bladder cancer risk: Dietary glycaemic index: Pasta: Bread: Whole grains

Worldwide, bladder cancer is the most frequent malignant tumour of the urinary tract, with approximately 420000 new cases each year with 4-fold higher incidence rates in men than in women ${ }^{(1)}$. Although tobacco smoking is the major risk factor for the development of bladder cancer accounting for up to $30-50 \%$ of cases $^{(2)}$, hyperglycaemia and hyperinsulinaemia may play a role in initiation and progression.

Conditions characterised by long-term hyperinsulinaemia and hyperglycaemia, such as the metabolic syndrome and type 2 diabetes, have been identified as risk factors for bladder cancer incidence and mortality ${ }^{(3-7)}$. In particular, a 10-year prospective study including more than a million people found significantly higher mortality for bladder cancer in men with blood glucose levels $>6.9 \mathrm{mmol} / \mathrm{l}$, after adjusting for smoking, age and alcohol drinking ${ }^{(4)}$. Furthermore, poorly controlled glycaemia (glycated $\mathrm{Hb}(\mathrm{HbA} 1 \mathrm{c})>53 \mathrm{mmol} / \mathrm{mol}$ or $>7.0 \%$ ) in people with diabetes increased the risk of recurrence of specific types of bladder cancer compared with good glycaemic control $(\mathrm{HbA} 1 \mathrm{c}<53 \mathrm{mmol} / \mathrm{mol} \text { or }<7.0 \%)^{(8,9)}$. These data suggest that lifestyle factors promoting hyperglycaemia may play a role in

Abbreviations: GI, glycaemic index; GL, glycaemic load.

* Corresponding author: L. S. A. Augustin, email livia.augustin@utoronto.ca 
bladder carcinogenesis. High glycaemic index (GI) and glycaemic load (GL) foods raise blood glucose levels even in the absence of diabetes, obesity and the metabolic syndrome. These foods increase blood glucose levels to a greater extent than the equivalent amount of carbohydrates consumed from low-GI foods ${ }^{(10)}$. High-GI diets have been associated with greater risk of cancer ${ }^{(11,12)}$ including bladder cancer in North American populations ${ }^{(13,14)}$.

To provide further information on the association between dietary GI/GL and bladder cancer risk in a Mediterranean area, we examined data from an Italian case-control study.

\section{Methods \\ Study subjects}

Between 2003 and 2014, we conducted a case-control study on bladder cancer within an established Italian network of collaborating centres, including Aviano and Milan in northern Italy, and Naples and Catania in southern Italy ${ }^{(15)}$

Cases were 690 patients aged between 25 and 84 years (median age: 67 years) with incident bladder cancer diagnosis, admitted to major general hospitals in the catchment areas. Nearly all cases ( $n$ 642, 93.0\%) were confirmed by histological testing on tumour tissue specimen from biopsy or surgery and three additional cases were confirmed by cytology only. Patients with self-reported history of diabetes mellitus ( $n$ 112) may include diet modification to control hyperglycaemia; therefore, they were excluded from the present analysis, leaving 578 cases (median age: 67 years).

Controls were 690 cancer-free patients aged between 27 and 84 years admitted to the same network of hospitals as cases for a wide spectrum of acute conditions unrelated to tobacco smoking, alcohol consumption or long-term diet modification. Controls were frequency-matched to cases by study centre, sex and age (in 5-year groups). In all, twenty-five controls were excluded after enrolment because of inappropriate admission diagnosis. After excluding subjects with self-reported history of diabetes mellitus ( $n$ 57), the total number of eligible controls was 608 (median age: 66 years). Of these, $28.3 \%$ were admitted for traumatic disorders, $22.5 \%$ for non-traumatic orthopaedic disorders, $38.7 \%$ for acute surgical conditions and $10.5 \%$ for other various illnesses. Less than $5 \%$ of cases and controls approached for interview during their hospital stay refused to participate for personal reasons. The power was adequate to detect $80 \%$ risk difference for variables with a prevalence of at least $20 \%$, at the usual $95 \%$ confidence limit. The present study was conducted according to the guidelines laid down in the Declaration of Helsinki and reported according to the STROBE guidelines ${ }^{(16)}$. All procedures involving human subjects were approved by the Ethic Boards of each study centre (Centro di Riferimento Oncologico (CRO)-Aviano, University of Milan, National Cancer Institute Pascale). All study subjects signed an informed consent before interview.

\section{Data collection}

Trained interviewers administered a structured questionnaire to cases and controls during hospitalisation. It included information on age, education and other socio-demographic characteristics, anthropometric measures, selected lifestyle habits (e.g. tobacco smoking), personal medical history and family history of cancer. The presence of abdominal obesity was defined using the International Diabetes Federation cutoff points (waist circumference $\geq 94 \mathrm{~cm}$ for men and $\geq 80 \mathrm{~cm}$ for women). As the information on waist circumference could not be obtained for technical reasons in 135 cases and 173 controls, we considered the $\mathrm{BMI} \geq 30 \mathrm{~kg} / \mathrm{m}^{2}$ as a proxy of abdominal obesity in patients missing waist circumference.

An interviewer-administered FFQ was used to assess dietary habits related to the 2 years preceding diagnosis/interview. This included seventy-eight foods, food groups or recipes (i.e. the most common ones in the Italian diet) structured into six sections: (i) bread, cereals and first courses; (ii) second courses (i.e. meat, fish and other main dishes); (iii) side dishes (i.e. vegetables); (iv) fruits; (v) desserts, sweets and soft drinks; (vi) milk, hot beverages and sweeteners. An additional section assessed the use of alcoholic beverages. Subjects were asked to indicate the average weekly frequency of consumption for each dietary item; intakes lower than once a week, but at least once a month, were coded as $0.5 /$ week. For fruit and vegetables subject to seasonal variation, consumption in season and the corresponding duration were elicited. The serving size was defined in 'natural' unit (e.g. 1 egg) or as an average serving in the Italian diet (e.g. $50 \mathrm{~g}$ of salad, $150 \mathrm{~g}$ of tomatoes). The FFQ was successfully tested for validity ${ }^{(17)}$ and reproducibility ${ }^{(18)}$. Total energy and carbohydrate intake was computed using an Italian food composition database ${ }^{(19)}$.

\section{Calculation of glycaemic index and glycaemic load}

For each carbohydrate-containing food, we expressed GI as a percentage of the glycaemic response elicited using white bread as a standard food, using international GI tables ${ }^{(20)}$. The average daily GI of each subject was computed by summing the products of the GI value of one serving of each food times the average number of servings of that food consumed by the subject per week divided by the weekly available carbohydrate ${ }^{(20,21)}$. In order to take into account Italian cooking habits (e.g. pasta 'al dente'), Italian sources were used for a few local recipes ${ }^{(22)}$. Food items for which a GI had not been determined were assigned the GI of the closest comparable food (e.g. tangerines were assigned the same GI of oranges). A score for the daily average GL was computed by summing the products of the GI value of one serving of each food times the average number of servings of that food consumed by the subject per week.

\section{Statistical analysis}

OR for bladder cancer and the corresponding 95\% CI were estimated using unconditional logistic regression models including terms for matching variables (study centre, sex, quinquennia of age), and potential confounders including years of education ( $<7,7-11, \geq 12$ years), smoking habits (never, former, current smokers of $<20$ and of $\geq 20$ cigarettes/d), alcohol drinking ( $<14,14-20, \geq 20$ drinks/week), abdominal obesity (yes/no) and total energy intake (kJ/d). GI, GL, available carbohydrates, bread and pasta were entered in the 
models as quartiles based on the distribution of controls, using the lowest quartile as the reference category. Given the low consumption, legumes and whole-grain products were categorised as use $v$. abstinence. Tests for trend were based on the likelihood-ratio test between the models with and without a linear term for each variable of interest. Heterogeneity across strata was tested by comparing the models with and without an interaction term for such variable ${ }^{(23)}$.

\section{Results}

Table 1 shows the distribution of cases and controls according to socio-demographic characteristics, smoking habits, alcohol

Table 1. Distribution of 578 bladder cancer cases and 608 controls according to socio-demographic characteristics and selected variables (Numbers and percentages, odds ratios and $95 \%$ confidence intervals)

\begin{tabular}{|c|c|c|c|c|c|c|}
\hline & \multicolumn{2}{|c|}{ Cases } & \multicolumn{2}{|c|}{ Controls } & \multirow[b]{2}{*}{$\mathrm{OR}^{*}$} & \multirow[b]{2}{*}{$95 \% \mathrm{Cl}$} \\
\hline & $n$ & $\%$ & $n$ & $\%$ & & \\
\hline \multicolumn{7}{|l|}{ Sex† } \\
\hline Man & 491 & $85 \cdot 0$ & 513 & $84 \cdot 4$ & & \\
\hline Woman & 87 & $15 \cdot 0$ & 95 & $15 \cdot 6$ & & \\
\hline \multicolumn{7}{|l|}{ Age (years) $†$} \\
\hline$<55$ & 78 & 13.5 & 105 & $17 \cdot 3$ & & \\
\hline $55-59$ & 53 & $9 \cdot 2$ & 68 & $11 \cdot 2$ & & \\
\hline $60-64$ & 91 & $15 \cdot 7$ & 107 & $17 \cdot 6$ & & \\
\hline $65-69$ & 137 & $23 \cdot 7$ & 129 & $21 \cdot 2$ & & \\
\hline $70-74$ & 125 & 21.6 & 113 & $18 \cdot 6$ & & \\
\hline$\geq 75$ & 94 & $16 \cdot 3$ & 86 & $14 \cdot 1$ & & \\
\hline \multicolumn{7}{|l|}{ Study centre† } \\
\hline Aviano & 202 & $35 \cdot 0$ & 233 & $38 \cdot 3$ & & \\
\hline Milan & 200 & $34 \cdot 6$ & 212 & 34.9 & & \\
\hline Naples & 111 & $19 \cdot 2$ & 96 & $15 \cdot 8$ & & \\
\hline Catania & 65 & $11 \cdot 2$ & 67 & $11 \cdot 0$ & & \\
\hline \multicolumn{7}{|l|}{ Education (years) $\ddagger$} \\
\hline$<7$ & 233 & 40.4 & 242 & $39 \cdot 8$ & $1 \S$ & \\
\hline $7-11$ & 196 & $34 \cdot 0$ & 201 & $33 \cdot 1$ & $1 \cdot 14$ & $0.86,1.52$ \\
\hline$\geq 12$ & 148 & $25 \cdot 6$ & 165 & $27 \cdot 1$ & 1.05 & $0.77,1.44$ \\
\hline $\bar{x}^{2}$ for trend & & & & & $P_{\text {for }}$ & trend $=0.68$ \\
\hline \multicolumn{7}{|l|}{ Smoking habits } \\
\hline Never & 85 & $14 \cdot 7$ & 218 & $35 \cdot 8$ & $1 \S$ & \\
\hline Former & 242 & 41.9 & 257 & $42 \cdot 3$ & 2.52 & $1 \cdot 82,3.49$ \\
\hline \multicolumn{7}{|l|}{ Current (cigarettes/d) } \\
\hline$<20$ & 139 & $24 \cdot 0$ & 81 & $13 \cdot 3$ & $5 \cdot 26$ & $3.57,7 \cdot 74$ \\
\hline$\geq 20$ & 112 & $19 \cdot 4$ & 52 & $8 \cdot 6$ & $7 \cdot 11$ & $4.58,11.04$ \\
\hline$x^{2}$ for trend & & & & & $P_{\text {for }}$ & trend $<0.01$ \\
\hline \multicolumn{7}{|l|}{$\begin{array}{l}\text { Alcohol drinking } \\
\text { (drinks/week) } \ddagger\end{array}$} \\
\hline$<14$ & 243 & $42 \cdot 1$ & 272 & $44 \cdot 8$ & $1 \S$ & \\
\hline $14-20$ & 185 & $32 \cdot 1$ & 197 & $32 \cdot 5$ & 1.05 & $0.80,1.39$ \\
\hline$\geq 21$ & 149 & $25 \cdot 8$ & 138 & $22 \cdot 7$ & $1 \cdot 27$ & $0.92,1.76$ \\
\hline$x^{2}$ for trend & & & & & $P_{\text {for }}$ & trend $=0.16$ \\
\hline \multicolumn{7}{|l|}{ Abdominal obesity } \\
\hline No & 246 & $42 \cdot 6$ & 296 & $48 \cdot 7$ & $1 \S$ & \\
\hline Yes & 332 & $57 \cdot 4$ & 312 & $51 \cdot 3$ & 1.33 & $1.05,1.69$ \\
\hline \multicolumn{5}{|l|}{ Total energy $(\mathrm{kJ} / \mathrm{d})$} & \multicolumn{2}{|c|}{$P=0.02$} \\
\hline$<7840$ & 141 & 24.4 & 152 & $25 \cdot 0$ & $1 \S$ & \\
\hline 7840 to $<9360$ & 138 & 23.9 & 152 & $25 \cdot 0$ & 1.02 & $0.73,1.41$ \\
\hline 9360 to $<11351$ & 163 & $28 \cdot 2$ & 152 & $25 \cdot 0$ & $1 \cdot 24$ & $0.89,1.73$ \\
\hline$\geq 11351$ & 136 & 23.5 & 152 & $25 \cdot 0$ & 1.07 & $0.75,1.53$ \\
\hline$x^{2}$ for trend & & & & & & trend $=0.46$ \\
\hline
\end{tabular}

* Estimated by logistic regression model adjusted for sex, age and study centre. $\uparrow$ Matching variable.

¥ The sum does not add up to total because of missing values, one case for education, one case and one control for alcohol.

$\S$ Reference category. drinking, abdominal obesity and total energy intake. Compared with never smokers, heavy smokers (i.e. $\geq 20$ cigarettes/d) reported a 7 -fold increase in bladder cancer risk (95\% CI 4.58, 11.04) with a significant risk trend for number of cigarettes $(P<0 \cdot 01)$. Patients with abdominal obesity showed a significantly higher risk of bladder cancer (OR 1.33; $95 \%$ CI 1.05, 1.69) as compared with those without this condition. No significant association emerged for education, alcohol drinking and total energy intake.

Table 2 gives the OR for bladder cancer according to quartiles of available carbohydrates, GI, GL and selected carbohydraterich food groups. No significant associations emerged for total available carbohydrates (OR 1.52; $95 \%$ CI 0.85, 2.69) and for GI (OR 1.18; $95 \%$ CI $0.83,1.67$ ), whereas a significant direct association was observed for GL, with an OR of 1.96 (95\% CI $\left.1 \cdot 16,3 \cdot 31 ; P_{\text {for trend }}<0 \cdot 01\right)$. Bread was directly associated with bladder cancer risk with OR of 1.64 (95\% CI 1.14, 2.35) and 1.92 (95\% CI 1.28, 2.86) for the third and fourth quartiles, respectively, compared with the lowest quartile $\left(P_{\text {for trend }}<0 \cdot 01\right)$. Similarly, elevated pasta consumption was associated with increased bladder cancer (OR 1.58; 95\% CI 1.09, $2 \cdot 29$ in the highest $v$. the lowest quartile of intake; $\left.P_{\text {for trend }}=0.03\right)$. The association with pasta was significant in men only (OR 1.81; $95 \%$ CI $\left.1.20,2 \cdot 73 ; P_{\text {for trend }}<0.01\right)$, but no heterogeneity was observed between men and women $(P=0 \cdot 26)$. Although not significant, high regular use of whole-grain products and legumes showed an inverse association with bladder cancer risk (OR 0.82; 95\% CI 0.63, 1.08 and OR 0.78; 95\% CI 0.60, 1.00, respectively), as compared with abstainers. No heterogeneity emerged according to sex $\left(P_{\text {for heterogeneity }} \geq 0 \cdot 05\right)$.

As vegetables and related seasoning, particularly olive oil, may counteract the glycaemic response of food, the associations between bladder cancer risk and available carbohydrates, GI, GL and intake of bread and pasta were further analysed in separate strata of vegetable intake (Table 3). Although no significant heterogeneity emerged for all the considered food items, results were suggestive that the effect for elevated GL was stronger among people with vegetable consumption below the median (i.e. $160 \mathrm{~g} / \mathrm{d}$ ) than among those above this level of consumption (OR 2.41 and 1.74 , respectively).

\section{Discussion}

Our study found that high dietary GL, an indicator of both quality and quantity of carbohydrate foods, and high intakes of bread and pasta were directly associated with bladder cancer risk. Interestingly, these associations were less strong in people with elevated vegetable consumption.

Two other studies, one conducted in the USA and one in Canada, investigated the association of dietary GI and GL and bladder cancer risk and found an increased risk with higher GI but no association with $\mathrm{GL}^{(13,14)}$. The apparent discrepancy in results may be because of different dietary habits in different countries. In the US study, the first quantile of GL started at very low values compared with the present Italian population, where diets are very rich in total carbohydrates. The dietary GL is the product of each food's GI (derived from GI testing of foods in human subjects) by the amount of total available carbohydrates present in the same food (excluding unavailable carbohydrate 
Table 2. Distribution of 578 bladder cancer cases (Ca) and 608 controls (Co), according to available carbohydrates, glycaemic index, glycaemic load, bread, pasta, legumes and whole-grain products (Odds ratios and $95 \%$ confidence intervals)

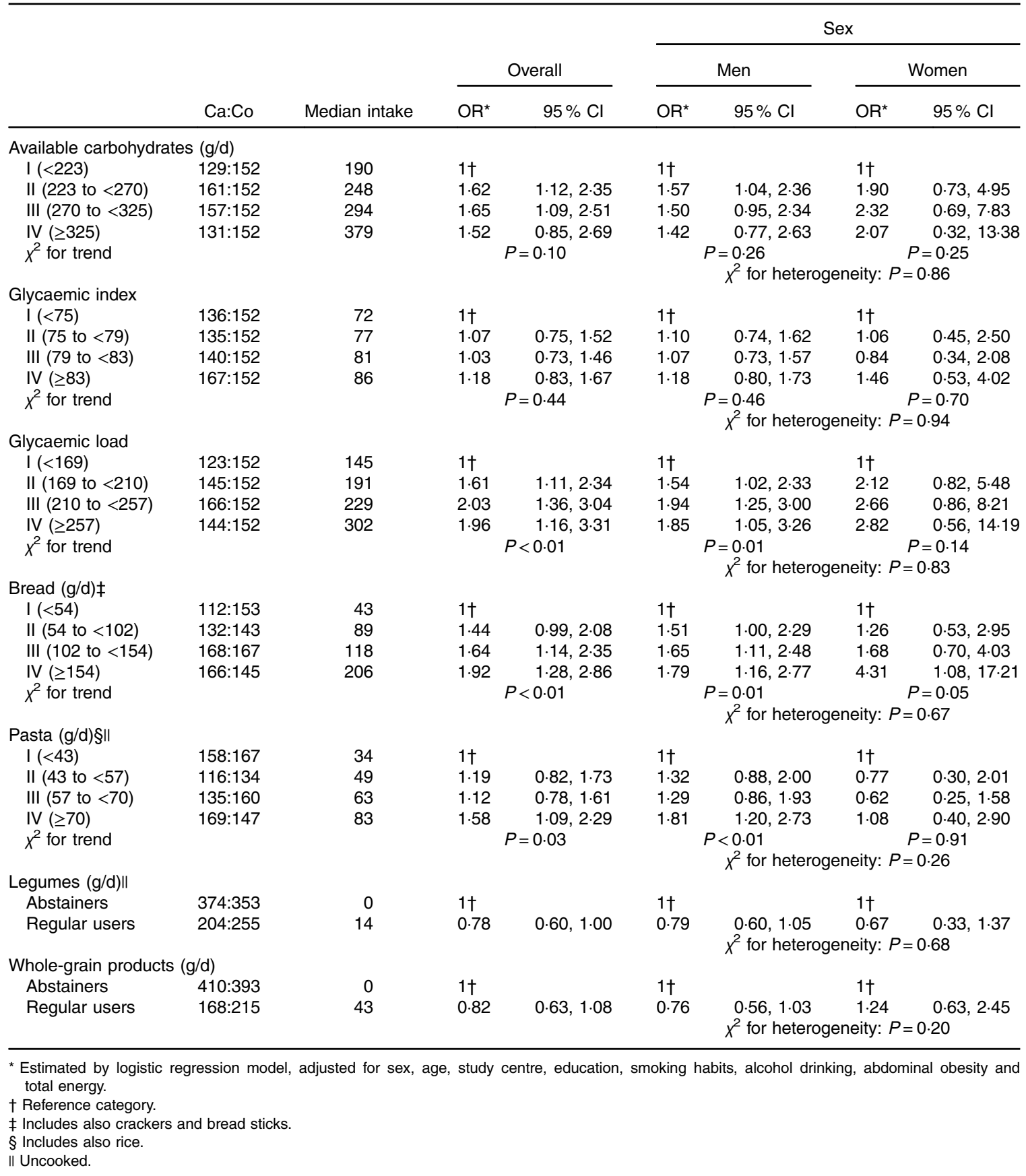

such as fibre). A low-GL diet can be achieved by either consuming low-GI foods or by consuming small amounts of carbohydrate foods with any GI value or by consuming both low-GI foods and small quantity of carbohydrate foods. Considering that the Mediterranean-Italian diet is characterised by frequent (e.g. daily) consumption of pasta (a medium-low GI food), a high GL in Italy may be the result of very large quantities of carbohydrates. High-carbohydrate diets, as typically seen in Italy, may need to include very low-GI foods to show an impact on glycaemia. With the shift of the
Mediterranean diet towards more convenient and fast food choices, lower-GI foods such as legumes, have become less frequent on the plates of many Italians ${ }^{(24)}$. It is possible that in bladder cancer a high carbohydrate intake may confound any potential association with GI. Diets with low GI $(<69$ on a bread scale) and low GL are considered more beneficial to overall health, especially in environments characterised by sedentary behaviour, excess energy intake and excess body weight ${ }^{(25)}$. Reducing the glycaemic impact of the overall diet with low-GI/ GL foods has been shown to decrease concentrations of fasting 
Table 3. Distribution of 578 bladder cancer cases and 608 controls, according to quartiles of available carbohydrates, glycaemic index, glycaemic load, consumption of bread and pasta, in strata of vegetable intake (Odds ratios and $95 \%$ confidence intervals)

\begin{tabular}{|c|c|c|c|c|c|}
\hline & \multirow[b]{3}{*}{ Median intake } & \multicolumn{4}{|c|}{ Vegetable intake $(\mathrm{g} / \mathrm{d})$} \\
\hline & & \multicolumn{2}{|c|}{$<160$} & \multicolumn{2}{|c|}{$\geq 160$} \\
\hline & & $\mathrm{OR}^{*}$ & $95 \% \mathrm{Cl}$ & $\mathrm{OR}^{\star}$ & $95 \% \mathrm{Cl}$ \\
\hline \multicolumn{6}{|c|}{ Available carbohydrates $(\mathrm{g} / \mathrm{d})$} \\
\hline I $(<223)$ & 190 & $1 \dagger$ & & $1 \dagger$ & \\
\hline II $(223$ to $<270)$ & 248 & 1.35 & $0.83,2.18$ & $2 \cdot 14$ & $1 \cdot 10,4 \cdot 17$ \\
\hline III $(270$ to $<325)$ & 294 & 1.86 & $1.02,3.40$ & 1.64 & $0.84,3.20$ \\
\hline IV $(\geq 325)$ & 379 & 1.67 & $0.68,4.06$ & 1.50 & $0.64,3.52$ \\
\hline \multirow[t]{2}{*}{$x^{2}$ for trend } & & \multicolumn{2}{|c|}{$P=0.09$} & \multicolumn{2}{|c|}{$P=0.61$} \\
\hline & & \multicolumn{4}{|c|}{$x^{2}$ for heterogeneity: $P=0.70$} \\
\hline \multicolumn{6}{|l|}{ Glycaemic index } \\
\hline $\mathrm{i}(<75)$ & 72 & $1 \dagger$ & & $1 \dagger$ & \\
\hline II $(75$ to $<79)$ & 77 & 1.36 & $0.83,2.24$ & 0.91 & $0.54,1.53$ \\
\hline III (79 to <83) & 81 & 1.41 & $0.86,2.32$ & 0.80 & $0.47,1.34$ \\
\hline IV $(\geq 83)$ & 86 & 1.35 & $0.82,2 \cdot 22$ & 0.93 & $0.54,1.60$ \\
\hline$x^{2}$ for trend & & \multirow{2}{*}{\multicolumn{4}{|c|}{$\begin{array}{c}P=0.26 \\
x^{2} \text { for heterogeneity: } P=0.18^{P=0.65}\end{array}$}} \\
\hline & & & & & \\
\hline \multicolumn{6}{|l|}{ Glycaemic load } \\
\hline | $(<169)$ & 145 & $1 \dagger$ & & $1 \dagger$ & \\
\hline II $(169$ to <210) & 191 & 1.43 & $0.88,2.32$ & 2.01 & $1.04,3.88$ \\
\hline III (210 to <257) & 229 & $2 \cdot 24$ & $1.26,3.99$ & 1.93 & $1.01,3.69$ \\
\hline IV $(\geq 257)$ & 302 & 2.41 & $1.06,5.47$ & 1.74 & $0.80,3.77$ \\
\hline$x^{2}$ for trend & & \multirow{2}{*}{\multicolumn{4}{|c|}{  }} \\
\hline & & & & & \\
\hline \multicolumn{6}{|l|}{ Bread $(g / d) \ddagger$} \\
\hline I $(<54)$ & 43 & $1 \dagger$ & & $1 \dagger$ & \\
\hline II $(54$ to $<102)$ & 89 & 1.37 & $0.85,2 \cdot 21$ & 1.49 & $0.81,2.75$ \\
\hline III $(102$ to $<154)$ & 118 & 1.71 & $1.05,2.77$ & 1.44 & $0.80,2.58$ \\
\hline IV $(\geq 154)$ & 206 & 1.83 & $1.02,3.31$ & 1.85 & $1.01,3.39$ \\
\hline \multirow[t]{2}{*}{$x^{2}$ for trend } & & \multirow{2}{*}{\multicolumn{4}{|c|}{$\begin{array}{c}P=0.02 \\
X^{2} \text { for heterogeneity: } P=0.96^{P=0.07}\end{array}$}} \\
\hline & & & & & \\
\hline \multicolumn{6}{|l|}{ Pasta $(g / d) \S \|$} \\
\hline $\mathrm{I}(<43)$ & 34 & $1 \dagger$ & & $1 \dagger$ & \\
\hline II $(43$ to $<57)$ & 49 & 1.06 & $0.65,1.72$ & 1.40 & $0.75,2 \cdot 60$ \\
\hline III $(57$ to $<70)$ & 63 & 1.04 & $0.65,1.67$ & $1 \cdot 19$ & $0 \cdot 65,2 \cdot 19$ \\
\hline IV $(\geq 70)$ & 83 & 1.73 & $1.03,2.92$ & 1.55 & $0.86,2.79$ \\
\hline \multirow{2}{*}{$x^{2}$ for trend } & & \multirow{2}{*}{\multicolumn{4}{|c|}{$\begin{aligned} P & =0.07 \\
& x^{2} \text { for heterogeneity: } P=0.86\end{aligned}$}} \\
\hline & & & & & \\
\hline
\end{tabular}

* Estimated by logistic regression model, adjusted for sex, age, study centre, education, smoking habits, alcohol drinking, abdominal obesity and total energy. $\dagger$ Reference category.

¥ Includes also crackers and bread sticks.

$\S$ Includes also rice

II Uncooked.

blood glucose, glycosylated proteins, insulin and inflammatory markers, and to reduce the risk of developing type 2 diabetes and some cancers ${ }^{(14,25)}$. Fasting hyperglycaemia $(>7 \cdot 0 \mathrm{mmol} / \mathrm{l})$ has been found to significantly increase bladder cancer risk in an Asian study including 1.3 million people aged 30-95 years ${ }^{(4)}$. Insulin can activate epidermal growth factors and protein kinases and in in vitro studies insulin increased bladder cancer cell proliferation in a time- and dose-dependent manner ${ }^{(26,27)}$. The diabetic medication metformin, which helps to control both glycaemia and insulin resistance, has been shown to reduce growth of malignant cell types including bladder cancer cells ${ }^{(28,29)}$. It is also possible that diets promoting large increases in blood glucose may promote urinary tract infections and hence increase bladder cancer risk ${ }^{(30)}$.

Two main staple carbohydrate foods of the Italian Mediterranean diet are bread (high GI) and pasta (medium-low GI), representing 24 and $16 \%$ of total carbohydrate intake, respectively ${ }^{(31)}$. Generally, the associations with cancer risk have been stronger for bread than for pasta ${ }^{(32,33)}$ and with a difference between sexes. In a previous Italian study investigating the association of pasta or bread and colorectal or breast cancer, the associations with bread were stronger in women than in men ${ }^{(32)}$. In the current study, bread, pasta and GL were directly and significantly associated with bladder cancer particularly in men. Men are generally affected by bladder cancer three to four times more often than women ${ }^{(34,35)}$, and several in vitro and animal studies suggest a potential involvement of sex steroid hormonal pathways ${ }^{(36)}$. Indeed, recent evidence suggests that androgen and androgen receptor may contribute to bladder carcinogenesis both through hormonal pathways and by other mechanisms such as reduced expression of detoxifying enzymes in the bladder ${ }^{(37,38)}$. It is possible that diets that increase blood glucose the most may favour higher testosterone bioavailability by reducing its binding protein ${ }^{(39)}$. 
Furthermore, the results of our study suggest that the associations between bladder cancer risk and GL may be stronger among people with a lower vegetable intake $(<160 \mathrm{~g} / \mathrm{d})$ than in those with higher intakes $(>160 \mathrm{~g} / \mathrm{d})$, possibly because of components present in vegetables (e.g. fibre and antioxidants) or consumed with vegetables (e.g. olive oil) that may modify the glycaemic response by various mechanisms (e.g. slowing carbohydrate absorption or reducing glucose toxicity to the beta cells) ${ }^{(40,41)}$

As for most case-control studies, information and selection biases were potential limitations of this study. Information bias, however, was minimised by the administration of the questionnaire to both cases and controls by the same trained interviewers, under similar conditions in a hospital setting. Differential recall in cases and controls in our study may be unlikely as the dietary hypothesis of GI and GL in bladder cancer risk was not known during the study and the questionnaire was satisfactorily reproducible ${ }^{(42)}$. However, as the information was collected after diagnosis, it is possible that early symptoms of the disease may have caused changes in the diet. To avoid these potential sources of bias, any relevant dietary change in the 2 years preceding interview were recorded and we excluded from the control group all subjects with diagnoses that might have implicated long-term dietary modifications (e.g. diabetes). Furthermore, a possible limiting factor in our analyses was for the calculation of abdominal obesity where waist circumference was missing in approximately $25 \%$ of cases and controls and $\mathrm{BMI} \geq 30 \mathrm{~kg} / \mathrm{m}^{2}$ was used as a proxy. BMI $\geq$ $30 \mathrm{~kg} / \mathrm{m}^{2}$ is considered a good proxy of abdominal obesity, and analyses conducted excluding patients with missing waist circumference did not show appreciable variation in risk magnitude. In addition, GI and GL values may have some variability according to specific foods and cooking methods. In particular, although pasta and rice have different glycaemic responses, they were assessed together in our FFQ. However, this information bias is unlikely to have an impact on risk estimates, as rice accounts for $<20 \%$ in this food group of this study population $^{(43)}$. The almost complete participation of identified cases and controls, and the use of a validated and reproducible questionnaire, contributed to strengthen our findings. Generalisability of our study results has the limitations discussed above, typical of a hospital case-control study.

In conclusion, this study showed that bladder cancer risk is directly associated with high dietary GL and with consumption of high quantity of refined carbohydrates. These associations were stronger in subjects reporting low vegetable consumption.

\section{Acknowledgements}

This work was partially supported by the Italian Foundation for Cancer Research (FIRC).

L. S. A. A.: compiled the glycaemic index database; L. S. A. A. and J. P.: interpreted the data; M. T., M. L., C. L. V., A. T., A. C., M. G., G. F. and J. P.: collected the data; M. T. and J. P.: analysed the data; L. S. A. A. and M. T.: wrote main sections of the manuscript; M. M.: coordinated the work and reviewed the manuscript; M. M., M. L., C. L. V., A. T., A. C., M. G., G. F., D. J. A. J., G. B. and D. S.: revised the analysis; M. L., M. M., C. L. V., A. T., A. C., M. G., G. F., D. J. A. J., G. B., D. S. and J. P.: revised the manuscript.
L. S. A. A. is the cofounder and coordinator of the International Carbohydrate Quality Consortium (ICQC), has received honoraria from the Nutrition Foundation of Italy (NFI, Milan) and from Legaltaliana per la LottaContro i Tumori (a non-profit organization for the fight against cancer). C. L. V. is Member of the Advisory Board of NFI (honorary), and expert consultant to MSL Italy and Sorematec. D. J. A. J. has received research grants from Saskatchewan Pulse Growers, the Agricultural Bioproducts Innovation Program through the Pulse Research Network, the Advanced Foods and Material Network, Loblaw Companies Ltd, Unilever, Barilla, the Almond Board of California, Agriculture and Agri-food Canada, Pulse Canada, Kellogg's Company, Canada, Quaker Oats, Canada, Procter \& Gamble Technical Centre Ltd, Bayer Consumer Care, Springfield, NJ, Pepsi/Quaker, International Nut \& Dried Fruit (INC), Soy Foods Association of North America, the Coca-Cola Company (investigator initiated, unrestricted grant), Solae, Haine Celestial, the Sanitarium Company, Orafti, the International Tree Nut Council Nutrition Research and Education Foundation, the Peanut Institute, the Canola and Flax Councils of Canada, the Calorie Control Council, the Canadian Institute of Health Research, the Canada Foundation for Innovation and the Ontario Research Fund. He has received in-kind supplies for the trial as research support from the Almond Board of California, Walnut Council of California, American Peanut Council, Barilla, Unilever, Unico, Primo, Loblaw Companies, Quaker (Pepsico), Pristine Gourmet, Bunge Limited, Kellogg Canada, and WhiteWave Foods. He has been on the speaker's panel, served on the scientific advisory board and/or received travel support and/or honoraria from the Almond Board of California, Canadian Agriculture Policy Institute, Loblaw Companies Ltd, the Griffin Hospital (for the development of the NuVal scoring system), the Coca-Cola Company, EPICURE, Danone, Diet Quality Photo Navigation (DQPN), FareWell, Verywell, True Health Initiative, Saskatchewan Pulse Growers, Sanitarium Company, Orafti, the Almond Board of California, the American Peanut Council, the International Tree Nut Council Nutrition Research and Education Foundation, the Peanut Institute, Herbalife International, Pacific Health Laboratories, Nutritional Fundamental for Health, Barilla, Metagenics, Bayer Consumer Care, Unilever Canada and Netherlands, Solae, Kellogg, Quaker Oats, Procter \& Gamble, the Coca-Cola Company, the Griffin Hospital, Abbott Laboratories, the Canola Council of Canada, Dean Foods, the California Strawberry Commission, Haine Celestial, PepsiCo, the Alpro Foundation, Pioneer Hi-Bred International, DuPont Nutrition and Health, Spherix Consulting and WhiteWave Foods, the Advanced Foods and Material Network, the Canola and Flax Councils of Canada, the Nutritional Fundamentals for Health, Agri-Culture and Agri-Food Canada, the Canadian Agri-Food Policy Institute, Pulse Canada, the Saskatchewan Pulse Growers, the Soy Foods Association of North America, the NFI, Nutra-Source Diagnostics, the McDougall Program, the Toronto Knowledge Translation Group (St. Michael's Hospital), the Canadian College of Naturopathic Medicine, The Hospital for Sick Children, the Canadian Nutrition Society, the American Society of Nutrition, Arizona State University, Paolo Sorbini Foundation and the Institute of Nutrition, Metabolism and Diabetes. He received an honorarium from the US Department of Agriculture to present the 2013 W.O. Atwater 
Memorial Lecture. He received the 2013 Award for Excellence in Research from the International Nut and Dried Fruit Council. He received funding and travel support from the Canadian Society of Endocrinology and Metabolism to produce mini cases for the Canadian Diabetes Association. He is a cofounder and member of the ICQC. His wife is a director and partner of Glycemic Index Laboratories, Inc., and his sister received funding through a grant from the St. Michael's Hospital Foundation to develop a cookbook for one of his studies.

All other authors declare that there are no conflicts of interest.

\section{References}

1. Forman D, Bray F, Brewster DH, et al. (2013) Cancer Incidence in Five Continents, Vol. X. Lyon: IARC Scientific Publication.

2. Freedman ND, Silverman DT, Hollenbeck AR, et al. (2011) Association between smoking and risk of bladder cancer among men and women. JAMA 306, 737-745.

3. Esposito K, Chiodini P, Colao A, et al. (2012) Metabolic syndrome and risk of cancer: a systematic review and metaanalysis. Diabetes Care 35, 2402-2411.

4. Jee SH, Ohrr H, Sull JW, et al. (2005) Fasting serum glucose level and cancer risk in Korean men and women. JAMA 293, 194-202.

5. Montella M, Di Maso M, Crispo A, et al. (2015) Metabolic syndrome and the risk of urothelial carcinoma of the bladder: a case-control study. BMC Cancer 15, 720.

6. Turati F, Polesel J, Di Maso M, et al. (2015) Diabetes mellitus and the risk of bladder cancer: an Italian case-control study. Br J Cancer 113, 127-130.

7. Zhu Z, Zhang X, Shen Z, et al. (2013) Diabetes mellitus and risk of bladder cancer: a meta-analysis of cohort studies. PLOS ONE 8, e56662.

8. Hwang EC, Kim YJ, Hwang IS, et al. (2011) Impact of diabetes mellitus on recurrence and progression in patients with non-muscle invasive bladder carcinoma: a retrospective cohort study. Int J Urol 18, 769-776.

9. Tai YS, Chen CH, Huang CY, et al. (2015) Diabetes mellitus with poor glycemic control increases bladder cancer recurrence risk in patients with upper urinary tract urothelial carcinoma. Diabetes Metab Res Rev 31, 307-314.

10. Jenkins DJ, Wolever TM, Taylor RH, et al. (1981) Glycemic index of foods: a physiological basis for carbohydrate exchange. Am J Clin Nutr 34, 362-366.

11. Barclay AW, Petocz P, McMillan-Price J, et al. (2008) Glycemic index, glycemic load, and chronic disease risk-a meta-analysis of observational studies. Am J Clin Nutr 87, 627-637.

12. Choi Y, Giovannucci E \& Lee JE (2012) Glycaemic index and glycaemic load in relation to risk of diabetes-related cancers: a meta-analysis. Br J Nutr 108, 1934-1947.

13. George SM, Mayne ST, Leitzmann MF, et al. (2009) Dietary glycemic index, glycemic load, and risk of cancer: a prospective cohort study. Am J Epidemiol 169, 462-472.

14. Hu J, La Vecchia C, Augustin LS, et al. (2013) Glycemic index, glycemic load and cancer risk. Ann Oncol 24, 245-251.

15. Polesel J, Bosetti C, Di Maso M, et al. (2014) Duration and intensity of tobacco smoking and the risk of papillary and non-papillary transitional cell carcinoma of the bladder. Cancer Causes Control 25, 1151-1158.

16. von Elm E, Altman DG, Egger M, et al. (2007) The Strengthening the Reporting of Observational Studies in Epidemiology (STROBE) statement: guidelines for reporting observational studies. Ann Intern Med 147, 573-577.
17. Decarli A, Franceschi S, Ferraroni M, et al. (1996) Validation of a food-frequency questionnaire to assess dietary intakes in cancer studies in Italy. Results for specific nutrients. Ann Epidemiol 6, 110-118.

18. Franceschi S, Negri E, Salvini S, et al. (1993) Reproducibility of an Italian food frequency questionnaire for cancer studies: results for specific food items. Eur J Cancer 29A, 2298-2305.

19. Gnagnarella P, Parpinel M, Salvini S, et al. (2004) The update of the Italian food composition database. J Food Comp Anal 17, 509-522.

20. Atkinson FS, Foster-Powell K \& Brand-Miller JC (2008) International tables of glycemic index and glycemic load values: 2008. Diabetes Care 31, 2281-2283.

21. Wolever TM, Nguyen PM, Chiasson JL, et al. (1994) Determinants of diet glycemic index calculated retrospectively from diet records of 342 individuals with non-insulin-dependent diabetes mellitus. Am J Clin Nutr 59, 1265-1269.

22. Brighenti F \& Casiraghi M (1992) Influenza dei processi di trasformazione sulla risposta glicemica ad alimenti amidacei. G Ital Nutrizione Clin Prev 1, 79-87.

23. Breslow NE \& Day NE (1980) Statistical methods in cancer research. Volume I -the analysis of case-control studies. IARC Sci Publ 32, 5-338.

24. Giampaoli S, Krogh V, Grioni S, et al. (2015) Eating behaviours of Italian adults: results of the Osservatorio epidemiologico cardiovascolare/Health Examination Survey. Epidemiol Prev 39, 373-379.

25. Augustin LS, Kendall CW, Jenkins DJ, et al. (2015) Glycemic index, glycemic load and glycemic response: An International Scientific Consensus Summit from the International Carbohydrate Quality Consortium (ICQC). Nutr Metab Cardiovasc Dis 25, 795-815.

26. Liu S, Li Y, Lin T, et al. (2011) High dose human insulin and insulin glargine promote T24 bladder cancer cell proliferation via PI3K-independent activation of Akt. Diab Res Clin Pract 91, 177-182.

27. Ornskov D, Nexo E \& Sorensen BS (2006) Insulin-induced proliferation of bladder cancer cells is mediated through activation of the epidermal growth factor system. FEBS J $\mathbf{2 7 3}$, 5479-5489.

28. Zhang T, Guo P, Zhang Y, et al. (2013) The antidiabetic drug metformin inhibits the proliferation of bladder cancer cells in vitro and in vivo. Int J Mol Sci 14, 24603-24618.

29. Soranna D, Scotti L, Zambon A, et al. (2012) Cancer risk associated with use of metformin and sulfonylurea in type 2 diabetes: a meta-analysis. Oncologist 17, 813-822.

30. Brown JS, Wessells H, Chancellor MB, et al. (2005) Urologic complications of diabetes. Diabetes Care 28, 177-185.

31. Sette S, Le Donne C, Piccinelli R, et al. (2013) The third National Food Consumption Survey, INRAN-SCAI 2005-06: major dietary sources of nutrients in Italy. Int J Food Sci Nutr 64, 1014-1021.

32. Augustin LS, Malerba S, Lugo A, et al. (2013) Associations of bread and pasta with the risk of cancer of the breast and colorectum. Ann Oncol 24, 3094-3099.

33. Farvid MS, Cho E, Eliassen AH, et al. (2016) Lifetime grain consumption and breast cancer risk. Breast Cancer Res Treat 159, 335-345.

34. Hartge P, Harvey EB, Linehan WM, et al. (1990) Unexplained excess risk of bladder cancer in men. J Natl Cancer Inst $\mathbf{8 2}$, $1636-1640$.

35. Torre LA, Siegel RL, Ward EM, et al. (2016) Global cancer incidence and mortality rates and trends-an update. Cancer Epidemiol Biomarkers Prev 25, 16-27.

36. Godoy G, Gakis G, Smith CL, et al. (2016) Effects of androgen and estrogen receptor signaling pathways on 
bladder cancer initiation and progression. Bladder Cancer $\mathbf{2}$, $127-137$.

37. Izumi K, Zheng Y, Hsu JW, et al. (2013) Androgen receptor signals regulate UDP-glucuronosyltransferases in the urinary bladder: a potential mechanism of androgen-induced bladder carcinogenesis. Mol Carcinog 52, 94-102.

38. Miyamoto H, Yang Z, Chen YT, et al. (2007) Promotion of bladder cancer development and progression by androgen receptor signals. J Natl Cancer Inst 99, 558-568.

39. Boering M, van Dijk PR, Logtenberg SJ, et al. (2016) Effects of intraperitoneal insulin versus subcutaneous insulin administration on sex hormone-binding globulin concentrations in patients with type 1 diabetes mellitus. Endocr Connect 5, 136-142.
40. Augustin LS, Franceschi S, Jenkins DJ, et al. (2002) Glycemic index in chronic disease: a review. Eur J Clin Nutr 56, 1049-1071.

41. Satija A, Bhupathiraju SN, Rimm EB, et al. (2016) Plant-based dietary patterns and incidence of type 2 diabetes in US men and women: results from three prospective cohort studies. PLoS Med 13, e1002039.

42. D'Avanzo B, La Vecchia C, Katsouyanni K, et al. (1997) An assessment, and reproducibility of food frequency data provided by hospital controls. Eur J Cancer Prev 6, 288-293.

43. Turrini A, Saba A, Perrone D, et al. (2001) Food consumption patterns in Italy: the INN-CA Study 1994-1996. Eur J Clin Nutr 55, 571-588. 